\title{
Intra-articular injection of PDGF-BB explored in a novel in vitro model mobilizes mesenchymal stem cells from the synovium into synovial fluid in rats
}

\section{Kentaro Endo}

Tokyo Ika Shika Daigaku

Kiyotaka Horiuchi

Tokyo Ika Shika Daigaku

Hisako Katano

Tokyo Ika Shika Daigaku

Nobutake Ozeki

Tokyo Ika Shika Daigaku

Yuriko Sakamaki

Tokyo Ika Shika Daigaku

\section{Hideyuki Koga}

Tokyo Ika Shika Daigaku

Ichiro Sekiya ( $\nabla$ sekiya.arm@tmd.ac.jp )

Tokyo Ika Shika Daigaku https://orcid.org/0000-0002-6331-722X

\section{Research Article}

Keywords: mesenchymal stem cells, migration, synovium, synovial fluid, platelet-derived growth factor

Posted Date: March 17th, 2021

DOl: https://doi.org/10.21203/rs.3.rs-309810/v1

License: (c) (1) This work is licensed under a Creative Commons Attribution 4.0 International License. Read Full License

Version of Record: A version of this preprint was published at Stem Cell Reviews and Reports on March 26th, 2021. See the published version at https://doi.org/10.1007/s12015-021-10156-4. 


\section{Abstract \\ Background}

Drugs that can induce mesenchymal stem cell (MSC) mobilization from synovium into synovial fluid will enable regenerative medicine in joints without use of exogenous MSCs. An in vitro synovial MSC migration model had previously been developed for screening but had problems in practical application. We herein developed a novel in vitro model, explored cytokines for synovial MSC mobilization with this model, and verified whether MSCs in synovial fluid increase following intra-articular injection of the cytokine.

\section{Methods}

Human synovial MSCs embedded in a mixture of Matrigel and type 1 collagen hydrogel were placed on a culture insert and then put in medium containing migration factor. Of the six cytokines, we identified the one that mobilizes the highest number of MSCs. PDGF-BB or PBS was injected into rat knees, and $48 \mathrm{~h}$ later, synovial fluid was collected and cultured. The cells were examined for MSC properties.

\section{Results}

PDGF-BB was the most effective for synovial MSC mobilization among six cytokines. The effect of PDGF-BB was inhibited by a PRGFR inhibitor. Injection of PDGF-BB into rat knees increased colonyforming cells in the synovial fluid. These cells had surface epitopes and multipotency comparable to MSCs and a higher capacity for proliferation, colony formation, and chondrogenesis.

\section{Conclusions}

This novel in vitro model recapitulated the migration of MSCs from synovium into synovial fluid. Our exploration of cytokines revealed that PDGF-BB strongly induced in vitro synovial MSC migration, while intra-articular injection of PDGF-BB increased in vivo MSC numbers in synovial fluid in rats.

\section{Introduction}

Mesenchymal stem cells (MSCs) are defined by adhesion to plastic dishes, expression of specific surface epitopes, and multipotent differentiation potential [1]. MSCs in the synovial fluid of the knee increase in number after injury to the anterior cruciate ligament [2], meniscus [3], or cartilage [4]. These MSCs in the synovial fluid share characteristics with those normally present in the synovium [2]. Exogenous synovial MSCs injected into a knee with injured cartilage and meniscus adhere to the injured tissues and promote the repair in animal models [5-7]. These findings suggest that injury of intra-articular tissues and subsequent synovitis cause a mobilization of endogenous MSCs from the synovium into the synovial 
fluid. These MSCs then attach to the injured tissues and promote repair [8, 9]. However, the number of endogenous MSCs in the synovial fluid may be too small for spontaneous healing of the injured tissues in most cases. Therefore, discovery of a drug that could induce the mobilization of MSCs from the synovium into the synovial fluid without provoking inflammation could enable regenerative medicine without the need for injection of exogenous MSCs.

We previously developed a suspended synovium culture model for screening of drugs that could induce MSC mobilization from synovium $[10,11]$. The model consisted of one gram of human synovium suspended with a thread in a bottle containing $40 \mathrm{~mL}$ of culture medium. A $3.5 \mathrm{~cm}$ diameter culture dish was placed at the bottom of the bottle. The suspended synovium released synovial MSCs, and colonyforming cells were detected in the culture dish after seven days. This model was useful because the MSCs mobilized from the synovium could be easily quantified by colony counts, but it was also problematic because each piece of synovium varied in size, shape, and composition.

We have since refined and developed a novel in vitro synovial MSC migration model to overcome this limitation of the previous model. The synovium matrix consists mainly of basement membrane matrix and type 1 collagen [12], so we constructed an artificial synovium consisting of human synovial MSCs embedded in a mixture of Matrigel and type 1 collagen hydrogel. This was placed on a culture insert in a medium containing a candidate migration factor and the migrated cells were counted on the lower side of the insert.

The present study had three main goals. The first was to evaluate the new model for its usefulness. The second was to evaluate cytokines known to promote cell migration in various experimental systems for their ability to mobilize synovial MSCs. The third goal was to inject a representative cytokine detected by our screening system into rat knees to verify whether MSCs would increase in number in the synovial fluid in vivo.

\section{Materials And Methods}

\section{Culture of human and rat synovial MSCs}

Appropriate approvals were obtained for this study from the Medical Research Ethics Committee and the Animal Committee of our facility for the human and rat synovium harvesting, respectively. Human synovium was harvested from the knees of six osteoarthritis (OA) patients who underwent total knee arthroplasty (age range 59-84 years; two males and four females). Rat synovium was harvested from the knees of 11-week-old Lewis rats. The harvested synovium was minced with a scalpel and digested in $3 \mathrm{mg} / \mathrm{mL}$ collagenase (Sigma, St. Louis, MO, USA) for $3 \mathrm{~h}$ at $37^{\circ} \mathrm{C}$. The resulting nucleated cells were filtered through a $70 \mu \mathrm{m}$ cell strainer (Greiner Bio-One, Kremsmunster, Austria), plated in $145 \mathrm{~cm}^{2}$ dishes at a density of 2000 cells $/ \mathrm{cm}^{2}$, and expanded in growth medium consisting of a-minimum essential medium (a-MEM; Invitrogen, Carlsbad, CA, USA), 10\% fetal bovine serum (FBS; Invitrogen), and 1\% antibiotic-antimycotic (Invitrogen) at $37^{\circ} \mathrm{C}$ in a $5 \% \mathrm{CO}_{2}$ atmosphere. Confluent cells were detached with 
$0.25 \%$ trypsin and $1 \mathrm{mM}$ EDTA (Invitrogen) and cryopreserved in growth medium supplemented with 5\% dimethyl sulfoxide (Wako, Tokyo, Japan) for future use.

\section{In vitro synovial MSC migration model}

Synovial MSCs at passage 1 were serum-starved in a-MEM supplemented with $0.5 \%$ FBS for $24 \mathrm{~h}$. The cells were suspended in a solution containing $2 \mathrm{mg} / \mathrm{mL}$ type 1 collagen (Corning, NY, USA) and $2 \mathrm{mg} / \mathrm{mL}$ growth factor-reduced Matrigel (Corning) at a density of $2 \times 10^{6} \mathrm{cells} / \mathrm{mL}$, and then $60 \mu \mathrm{L}$ was placed onto transwell inserts with $8.0 \mu \mathrm{m}$ pores (Corning) in 24-well plates (Corning). The hydrogels were solidified for $30 \mathrm{~min}$ at $37^{\circ} \mathrm{C}$ and then $140 \mu \mathrm{L} 0.5 \% \mathrm{FBS}$ was added to the upper chamber. An $800 \mu \mathrm{L}$ volume of either $0.5 \%$ or $10 \%$ FBS was added to the lower chamber as a negative and positive control, respectively. The migration assays were performed in triplicate. After 12,24 , and $48 \mathrm{~h}$ incubation at $37^{\circ} \mathrm{C}$ in $5 \% \mathrm{CO}_{2}$, the inserts were fixed with $10 \%$ formalin in a neutral buffer solution (Wako) and stained with $0.5 \%$ crystal violet. The gels on the upper side of the inserts were then removed with a cotton swab. The lower side of the inserts viewed by light microscopy (BZ-X700, Keyence Co., Ltd., Osaka, Japan) and photographed, and the numbers of migrating cells were counted in five randomly selected fields $(\times 200)$.

\section{Pretreatment of inflammatory cytokines to synovial MSCs}

Synovial MSCs were cultured in 0.5\% FBS containing $10 \mathrm{ng} / \mathrm{mL}$ recombinant human interleukin-1 $\beta$ (IL-1 $\beta$; R\&D Systems, Minneapolis, MN, USA) and tumor necrosis factor- $a$ (TNF-a; R\&D Systems) for $24 \mathrm{~h}$. The cells were then detached and subjected to migration assay for $48 \mathrm{~h}$.

\section{Exploration of cytokines for synovial MSC mobilization}

We used recombinant human bone morphogenetic protein-2 (BMP-2; Medtronic, Minneapolis, MN, USA), hepatocyte growth factor (HGF; Peprotech, Rocky Hill, NJ, USA), insulin-like growth factor-1 (IGF-1; Peprotech), platelet-derived growth factor-AA (PDGF-AA; R\&D Systems), PDGF-AB (R\&D Systems), PDGFBB (R\&D Systems), PDGF-CC (R\&D Systems), PDGF-DD (R\&D Systems), stromal cell-derived factor-1a (SDF-1 $\alpha$; R\&D Systems), transforming growth factor- $\beta 3$ (TGF- $\beta 3$; Miltenyi Biotec, Bergisch Gladbach, Germany). The medium containing $0.5 \%$ FBS in the lower chamber was supplemented with $100 \mathrm{ng} / \mathrm{mL}$ BMP-2, $100 \mathrm{ng} / \mathrm{mL}$ HGF, $100 \mathrm{ng} / \mathrm{mL}$ IGF-1, $10 \mathrm{ng} / \mathrm{mL}$ PDGF-BB, $100 \mathrm{ng} / \mathrm{mL}$ SDF- 1 a, or $10 \mathrm{ng} / \mathrm{mL}$ TGF- $\beta 3$. After $48 \mathrm{~h}$ incubation, migrated cells were counted. The PDGF isoforms were compared by adding PDGF$\mathrm{AA}, \mathrm{AB}, \mathrm{BB}, \mathrm{CC}$, or DD to the lower chamber at $100 \mathrm{ng} / \mathrm{mL}$. Crenolanib (Selleck Chemicals, Houston, TX, USA), an inhibitor of PDGF receptor (PDGFR) $\alpha$ and $\beta$, was added to both the upper and lower chambers during the migration assay.

\section{Transmission electron microscopy (TEM)}

The hydrogels were fixed in $2.5 \%$ glutaraldehyde in $0.1 \mathrm{M}$ phosphate buffer (PB) for $2 \mathrm{~h}$, post-fixed in PB buffered $1 \% \mathrm{OsO}_{4}$ for $2 \mathrm{~h}$, dehydrated in a graded series of ethanol, and then embedded in Epon 812 . Ultrathin sections $(70 \mathrm{~nm})$ were collected on copper grids and then double-stained with uranyl acetate 
and lead citrate [13]. The sections were observed by transmission electron microscopy (JEM-1400Flash, JEOL, Japan).

\section{PDGF-BB injection into rat knee joints}

All animal care and experiments were conducted in accordance with the institutional guidelines of the Animal Committee of our facility. Fourteen male Lewis rats at 14 weeks old were used for this study. Mean weight was $350 \pm 10 \mathrm{~g}$ (328 to $362 \mathrm{~g}$ ). All animals were housed at 2 animals per cage, allowed food and water ad libitum under a $12 \mathrm{~h}$ light/dark cycle, and acclimatized for 1 week before the start of the study. The animals were placed under general anesthesia with isoflurane and $100 \mathrm{ng}$ recombinant rat PDGF-BB (ProSpec-Tany TechnoGene, Rehovot, Israel) in $50 \mu \mathrm{L}$ PBS was injected with a 30G needle into left or right knee joint, which was randomly selected. As a control, $50 \mu \mathrm{L}$ PBS was injected into the other knee joint. Rats were euthanized $48 \mathrm{~h}$ after the intra-articular injection.

\section{Culture of colony-forming cells in rat synovial fluid}

Synovial fluid was collected from rat knee joints by pumping with $50 \mu \mathrm{L}$ PBS three times. The fluid was centrifuged and the sediments were plated in $145-\mathrm{cm}^{2}$ dish and cultured in growth medium at $37^{\circ} \mathrm{C}$ in $5 \%$ $\mathrm{CO}_{2}$. After 1 week of cultivation, the cells from 8 rats were fixed and stained with $0.5 \%$ crystal violet for colony counting. Colonies less than $1 \mathrm{~mm}$ in diameter were ignored. Colony-forming cells from the other 6 rats were pooled and further passaged at the density of $500 \mathrm{cells} / \mathrm{cm}^{2}$ to assess their MSC properties.

\section{Histology}

Matrigel-collagen hydrogels containing human synovial MSCs were fixed with $10 \%$ formalin in neutral buffer for $24 \mathrm{~h}$. Rat knee joints were fixed for 2 days and decalcified with 20\% EDTA (Wako) for 2-3 weeks. The hydrogels and knee joints were embedded in paraffin and specimens were cut into $5 \mu \mathrm{m}$ sections and stained with hematoxylin and eosin (HE). The severity of synovitis around anterior horn of medial meniscus was quantified using the score proposed by Krenn et al [14]. Immunohistochemistry of type I collagen was performed by incubating sections of the hydrogels with $0.3 \%$ hydrogen peroxide/methanol for 30 min and then blocking with 10\% normal goat serum (Abcam, Cambridge, UK). Rabbit anti-type I collagen antibody (Rockland Immunochemicals, Limerick, PA, USA) was applied at $4^{\circ} \mathrm{C}$ overnight. The slides were then washed and incubated with horseradish peroxidase (HRP)-linked second antibody (Abcam) for $1 \mathrm{~h}$ and then with diaminobenzidine (DAB) substrate (Dako, Glostrup, Denmark). All slides were counterstained with hematoxylin.

\section{Proliferation assay}

Colony-forming cells derived from rat synovial fluid at passage 1 were plated in 6-well plates at a density of 500 cells $/ \mathrm{cm}^{2}$. After 2, 4, and 6 days of cultivation, the number of cells in each well were counted. The effect of PDGF-BB on the proliferation ability of human and rat synovial MSCs was examined by culturing 5,000 cells in 96-well plates with or without PDGF-BB. After 24 and 48 h, Cell Counting Kit-8 
solution (Dojindo, Tokyo, Japan) was added and the cells were incubated for a further $2 \mathrm{~h}$. The optical density values were then measured at $450 \mathrm{~nm}$ with a micro-plate reader (Tecan, Männedorf, Switzerland). The cell proliferation rate was calculated based on a standard curve.

\section{Colony formation assay}

One hundred colony-forming cells derived from rat synovial fluid at passage 1 were plated in a $145-\mathrm{cm}^{2}$ dish and cultured for 14 days. The cells were fixed with $10 \%$ formalin in neutral buffer solution and stained with $0.5 \%$ crystal violet for colony counting. Colonies less than $2 \mathrm{~mm}$ in diameter were ignored.

\section{Flow cytometry}

Human synovial MSCs at passage 1 and colony-forming cells in rat synovial fluid at passage 1 were detached with TrypLE (Thermo Fisher Scientific, MA, USA) for $10 \mathrm{~min}$ and analyzed for surface markers. Human synovial MSCs were tested with PDGFRa-BV421 (BD Biosciences, San Jose, CA, USA) and PDGFRß-BB700 (BD Biosciences) antibodies. Colony-forming cells in rat synovial fluid were tested with CD44-PE (eBioscience, San Diego, CA, USA), CD90-PE-Cy7 (eBioscience), CD105-APC (Novus Biologicals, Littleton, CO, USA), CD34-PerCP-Cy5.5 (Novus Biologicals), and CD45-FITC (BD Pharmigen, San Jose, CA, USA) antibodies. Cells were incubated with conjugated antibodies at $4^{\circ} \mathrm{C}$ for $1 \mathrm{~h}$ in the dark. Isotype controls were prepared as a negative control. The cell fluorescence and percentage of antigen-positive cells were evaluated by flow cytometry with a FACSVerse instrument (BD Biosciences).

\section{Differentiation assay}

The chondrogenic ability was assayed by suspending $2.5 \times 10^{4}$ cells in a chondrogenic induction medium consisting of high glucose Dulbecco's Modified Eagle Medium (DMEM; Thermo Fisher Scientific), 1\% ITS+ Premix (BD Biosciences), $50 \mu \mathrm{g} / \mathrm{mL}$ ascorbate-2-phosphate, $40 \mu \mathrm{g} / \mathrm{mL}$ L-proline (Sigma), $100 \mathrm{nM}$ dexamethasone, $100 \mu \mathrm{g} / \mathrm{mL}$ pyruvate (Sigma), $1 \%$ antibiotic-antimycotic, $10 \mathrm{ng} / \mathrm{mL}$ TGF- $\beta 3$, and 500 $\mathrm{ng} / \mathrm{mL}$ BMP-2. The cells were placed in a $15 \mathrm{~mL}$ polypropylene tube and centrifuged at $450 \mathrm{~g}$ for $10 \mathrm{~min}$ to form cell pellets. After 3 weeks of cultivation in a chondrogenic induction medium, the pellets were weighed and embedded in paraffin. Sections ( $5 \mu \mathrm{m}$ thick) were stained with Safranin 0 to evaluate the production of glycosaminoglycan.

For adipogenic induction, colony-forming cells in rat synovial fluid at passage 1 were plated in 12-well plates and cultured in growth medium until confluent. The medium was then switched to an adipogenic induction medium consisting of growth medium supplemented with $0.5 \mathrm{mM}$ isobutyl-methylxanthine (Sigma), $100 \mu \mathrm{M}$ indomethacin (Sigma), $100 \mathrm{nM}$ dexamethasone (Wako), $4.5 \mathrm{mg} / \mathrm{mL}$ D-(+)-glucose (Sigma), and $10 \mu \mathrm{g} / \mathrm{mL}$ insulin (Wako). The medium was changed twice a week. After 2 weeks, the cells were stained with Oil Red O (Sigma). The amount of intracellular lipid was determined by extracting the Oil Red $O$ dye with $300 \mu \mathrm{L}$ isopropanol (Wako) and determining the optical density at $510 \mathrm{~nm}$ with an Infinite F200 PRO spectrophotometer (Tecan Systems Inc., San Jose, CA, USA). 
For osteogenic induction, 500 cells were plated in a $50 \mathrm{~cm}^{2}$ dish and cultured in growth medium for 7 days. The medium was then shifted to osteogenic induction medium consisting of growth medium supplemented with $50 \mu \mathrm{g} / \mathrm{mL}$ ascorbate-2-phosphate (Sigma), $20 \mathrm{mM} \beta$-glycerophosphate (Sigma), and $1 \mathrm{nM}$ dexamethasone. After 3 weeks, the cells were stained with alizarin red (Sigma). Calcification was quantified by extracting the alizarin red dye with $10 \%$ cetylpyridinium chloride in $10 \mathrm{mM} \mathrm{Na}_{2} \mathrm{PO}_{4}(\mathrm{pH} 7.0)$ and measuring the optical density at $560 \mathrm{~nm}$.

\section{Statistical analysis}

All data were expressed as mean \pm standard deviation. All statistical analyses were performed with EZR (Saitama Medical Center, Jichi Medical University, Saitama, Japan), which is a graphical user interface for R (The R Foundation for Statistical Computing, Vienna, Austria) [15]. The statistical analysis methods are described in each of the figure legends. Statistical significance was accepted at $p<0.05$.

\section{Results}

\section{In vitro synovial MSC migration model}

The synovium in the joint was mimicked by embedding human synovial MSCs were embedded in Matrigel-type I collagen hydrogels placed onto transwell inserts (Figure 1A). Histological sections showed that the cells were uniformly distributed in artificial synovium (Figure 1B). The effect of $10 \%$ FBS on synovial MSC migration was investigated as a positive control (Figure 1C). Treatment with $0.5 \%$ FBS as a negative control did not induce cell migration, but $10 \%$ FBS induced migration at $24 \mathrm{~h}$, with further migration at $48 \mathrm{~h}$ (Figure 1D). Quantitative analysis showed that the number of migrated cells was significantly higher in the 10\% FBS group than in the $0.5 \%$ FBS group at 24 and $48 \mathrm{~h}$ (Figure 1E).

\section{Effect of pretreatment with inflammatory cytokines on synovial MSC migration}

Since IL-1 $\beta$ and TNF- $\alpha$ are known to be associated with OA pathogenesis $[16,17]$, synovial MSCs were pretreated with these cytokines before the migration assay to mimic the effects of exposure to an inflammatory environment on MSC migration (Figure $2 A$ ). Pretreatment of cells with IL-1 $\beta$ and TNF- $a$ significantly increased the number of cells that migrated toward 10\% FBS (Figure 2B and C).

\section{Exploration of cytokines that induce synovial MSC mobilization}

Six cytokines previously reported to promote cell migration [18-24] were added to the lower chamber to explore factors responsible for synovial MSC migration (Figure 3A). IGF-1 significantly promoted the migration of synovial MSCs when compared with $0.5 \%$ FBS (Figure 3B and C). PDGF-BB had the greatest effect on migrating synovial MSCs and the response was greater than $10 \% \mathrm{FBS}$. No significant effect was observed with BMP-2, HGF, SDF-1a, or TGF-33. Possible effects of the mitogenic potency of PDGF-BB were determined by cell proliferation assays. PDGF-BB at $100 \mathrm{ng} / \mathrm{ml}$ significantly stimulated the 
proliferation of human synovial MSCs but did not stimulate at the $10 \mathrm{ng} / \mathrm{ml}$ concentration used for migration assays (Fig 3D).

\section{Tracks in the matrix by mobilization of human synovial MSCs}

Mobilizing cells are known to generate tracks in a 3D matrix [25,26]; therefore, the cross section of the hydrogel was examined. Immunostaining images of type I collagen showed more tracks in the matrix of the PDGF-BB group than of the control group, despite a comparable cell distribution in both groups (Fig. $4 A)$. The TEM images showed a greater length of the unstructured regions adjacent to the cells along the long axis of the cells in the PDGF-BB group than in the control group (Fig. 4B).

\section{Effect of PDGF signaling on mobilization of human synovial MSCs}

Different PDGF isoforms were also examined for their effects on synovial MSC migration. All tested PDGF isoforms (PDGF-AA, - $A B,-B B,-C C$, and -DD) significantly promoted the migration of synovial MSCs when compared with $0.5 \%$ FBS (Figure $5 \mathrm{~A}$ ). Of the five isoforms, PDGF-BB showed the greatest effect. Flow cytometry confirmed that human synovial MSCs expressed both PDGFRa and $\beta$ (Figure 5B). Fewer synovial MSCs migrated toward PDGF-BB following addition of crenolanib, a PDGFRa and $\beta$ inhibitor, and the response was dose dependent (Figure 5C).

\section{PDGF-BB injection into rat knee joints}

PDGF-BB or PBS was injected into a rat knee, and $48 \mathrm{~h}$ later, synovial fluid and knee joints were collected to investigate in vivo effect of PDGF-BB (Figure 6A). The colony number per knee seven days after plating the synovial fluid was $331 \pm 196$ for the PDGF-BB-injected knees and $64 \pm 47$ for the PBS-injected knees, or a 5-fold increase with PDGF-BB (Figure 6B and C). Histological evaluation showed that synovitis was similar in the PDGF-BB-treated and PBS-treated knees (Figure 6D and E). The possibility that the mitogenic potency of PDGF-BB might have affected the results was examined by performing cell proliferation assays. PDGF-BB at $10 \mathrm{ng} / \mathrm{ml}$ promoted the proliferation of rat synovial MSCs in a monolayer culture, and PDGF-BB at $100 \mathrm{ng} / \mathrm{ml}$ further promoted this proliferation (Fig 6F).

\section{Properties of colony-forming cells in synovial fluid after PDGF-BB injection}

The properties of colony-forming cells derived from synovial fluid after PDGF-BB injection were examined from an MSC perspective (Figure 7A). Injection of PDGF-BB did not affect cell morphology (Figure 7B), but it did significantly increase cell proliferation (Figure 7B) and colony forming potential (Figure 7C). Colony-forming cells derived from synovial fluid after PDGF-BB injection showed high expression of CD44 and CD90, moderate expression of CD105, and no expression of CD34 and CD45. This surface epitope pattern was comparable to the patterns observed in cells obtained after PBS injection (Figure 7D). Colony-forming cells derived from synovial fluid after PDGF-BB injection could differentiate into cartilage (Figure 7E) and adipocytes (Figure 7F), and undergo calcification (Figure 7G). Injection of PDGF-BB enhanced cartilage extracellular matrix formation and lipid production but did not affect mineralized nodules. 


\section{Discussion}

We first reported a novel in vitro migration model in which human synovial MSCs embedded in a mixture of Matrigel and type I collagen hydrogel migrated in response to a migration factor. We confirmed that MSCs migrated along the gradient of FBS used as a positive control. This model had advantages of requiring only a small amount of medium and exhibiting a more uniform distribution of cells when compared to the suspended synovium culture model reported previously $[10,11]$. The synovial MSCs continued to migrate for the entire $48 \mathrm{~h}$ of the experiment, indicating that the chemoattractant gradient was maintained for that duration. This probably reflects a slowing down of the diffusion of the attractant molecules by the extracellular matrix gel [27]. Traditional chemotaxis assays using transwell inserts without gel can only maintain a concentration gradient for a few hours [28]. However, the half-life of an experimental intra-articular injection of albumin was $13-30 \mathrm{~h}[29,30]$; therefore, our model allows for a longer analysis than the traditional transwell method and more closely mimics the environment in the joint.

In the present study, we used this model to attempt to replicate the environment of OA. Synovial MSCs were pretreated with IL-1 $\beta$ and TNF- $\alpha$, since these are known to be the key cytokines associated with OA pathogenesis $[16,17]$. Pretreatment with IL-1 $\beta$ and TNF- $a$ significantly increased the number of migrated synovial MSCs. The number of MSCs in synovial fluid is known to increase in OA knees [4]. Our model mimicked the inflammatory environment of OA from the viewpoint of the migration of MSCs into the synovial fluid.

Our evaluation of different cytokines revealed that PDGF-BB strongly induced synovial MSC migration and that its effects were inhibited by a PRGFR inhibitor. PDGF-BB is a homodimer of PDGF $B$ chains and is involved in proliferation, differentiation, migration, and angiogenesis of various types of cells, including MSCs [31, 32]. PDGF-BB has been reported to promote the migration of bone marrow MSCs and fibroblast-like synovial cells in conventional chemotaxis assays using transwell inserts [21, 24]. This indicates that our model is useful for screening cytokines that promote the migration of synovial MSCs. We have also provided the first evidence that PDGF-DD has a stronger effect on synovial MSC migration than is observed with the other isoforms. The PDGFR has 3 dimer types, PDGFRaa, PDGFRaß, and PDGFR $\beta$. Of the five PDGF isoforms tested in the present study, only PDGF-BB and DD have a known affinity for PDGFRßB [33]. Both PDGF-BB and PDGF-DD induced a strong MSC migration in our model system, suggesting that PDGFR $\beta$ signaling plays an important role in the migration of synovial MSCs.

Immunohistological and TEM analysis showed that the human synovial MSCs stimulated with PDGF-BB generated many tracks in the hydrogel matrix. Sabeh et al. previously reported that mouse fibroblasts treated with PDGF-BB invaded collagen gels and formed tunnels in the matrix [34], in agreement with our observations. In the present study, supplying PDGF-BB at $10 \mathrm{ng} / \mathrm{ml}$ to explore migration factors did not result in a mitogenic effect in human synovial MSCs. These findings support the mobilization of synovial MSCs from the hydrogel to the lower side of the membrane without a promotion of cell division. 
IGF-1 also induced a weak enhancement of migration by synovial MSCs. By contrast, BMP-2, HGF, SDF$1 \mathrm{a}$, and TGF- $\beta 3$ did not induce the migration of synovial MSCs, despite previous reports of their chemotactic effects in conventional transwell chemotaxis assays using human bone marrow and adipose tissue-derived MSCs $[18,20,22,23]$. This finding indicates that those cytokines are ineffective in mobilizing gel-embedded synovial MSCs that mimic synovial tissue and suggests that injection of these cytokines into the joints of rats would not mobilize MSCs into the joint fluid.

Injection of PDGF-BB into the rat knees increased the number of colony-forming cells in synovial fluid by approximately 5 -fold, confirming that our in vitro model mimics the natural migration of MSCs from the synovium into synovial fluid. However, we cannot exclude the additional possibility that the increase in the number of colony-forming cells in the synovial fluid was due to the proliferative effect of PDGF-BB, as we found that PDGF-BB promoted the proliferation of rat synovial MSCs in a monolayer culture. The colony-forming cells isolated from synovial fluid were positive for CD44, CD90 and CD105 and negative for CD34 and CD45, and they also displayed chondrogenic, adipogenic, and osteogenic potentials. These characteristics demonstrate that colony-forming cells derived from synovial fluid meet the criteria for defining MSCs [1].

Colony-forming cells obtained from synovial fluid had higher capacities for proliferation, colony formation, and chondrogenesis when obtained from synovial fluid of knees injected with PDGF-BB than from synovial fluid of knees injected with PBS. Two possible reasons can be considered. One is that intraarticular injection of PDGF-BB selectively mobilized synovial MSCs with higher capacities for these processes into the synovial fluid. In our previous study, human synovial MSCs isolated from perivascular regions that were rich in cells with PDGFRs showed higher proliferative and chondrogenic capacities when compared with cells isolated from other regions that were poor in cell with PDGFRs [35]. Similar reports from other groups have indicated that both PDGFRa and $\beta$ are markers that identify MSCs with great potential $[36,37]$. Therefore, the MSCs mobilized by PDGF-BB might originate from the perivascular region. The other reason is that the injection of PDGF-BB affected MSCs in the synovial fluid while also having a proliferative effect on the subsequent monolayer culture in vitro. According to $\mathrm{Xu}$ et al., preconditioning of MSCs with PDGF-BB for $48 \mathrm{~h}$ significantly improved MSC-mediated cardioprotection in a mouse model of cardiac ischemia-reperfusion injury [38]. This suggests that MSCs pre-exposed to PDGF-BB might retain the beneficial effects of PDGF-BB, including enhanced proliferation.

We have demonstrated that the pharmacological manipulation of synovial fluid by intra-articular injection of a cytokine could increase the number of MSCs in synovial fluid without inducing further synovitis. Mechanical agitation of the synovium has been reported as a method for mobilizing MSCs into the synovial fluid [39]. Intra-articular injection is less invasive than that.

One limitation of this study is that no evaluation was made of a possible alteration in the number of MSCs in the synovium due to the migration of MSCs from the synovium into the synovial fluid after PDGF-BB injection. Future studies should therefore focus on the number of MSCs remaining in the synovium. Another limitation is that we have not yet clarified whether intra-articular injection of PDGF-BB 
actually promotes the repair and regeneration of cartilage and meniscus injury or if it inhibits the progression of OA. These are important issues to resolve before considering clinical application of PDGFBB.

In conclusion, we demonstrated the usefulness of a novel in vitro model that can recapitulate the migration of MSCs from the synovium into the synovial fluid. Our evaluation of several cytokines revealed that PDGF-BB strongly induced synovial MSC migration. Injection of PDGF-BB into rat knees also increased the number of MSCs in the synovial fluid.

\section{Declarations}

\section{Funding}

This study was supported by the Japan Society for the Promotion of Science (JSPS) KAKENHI (19K24026).

\section{Conflicts of interest}

The authors declare no conflict of interest.

\section{Ethics approval}

This study was approved by the Medical Research Ethics Committee of Tokyo Medical and Dental University, and informed consent was obtained from all study subjects. All animal experiments were approved by the Animal Experimentation Committee of Tokyo Medical and Dental University.

\section{Consent for publication}

All individuals consented to publication.

\section{Availability of data and material}

Not applicable.

\section{Code availability}

Not applicable.

\section{Authors' contributions}

KE designed the study, performed all experiments, and wrote the manuscript. KH provided ideas, contributed to acquisition of data, and revised the manuscript. HKa and NO provided ideas and revised the manuscript. YS contributed to acquisition of TEM data and revised the manuscript. HKo obtained informed consent, collected human tissues, and revised the manuscript. IS provided ideas, organized the data, and completed the manuscript. All authors read and approved the submitted draft of the paper. 
Acknowledgements

The authors thank Mika Watanabe and Kimiko Takanashi for managing our laboratory and Ellen Roider for English editing.

\section{Authors' information}

1 Center for Stem Cell and Regenerative Medicine, Tokyo Medical and Dental University, Tokyo, Japan

2 Research Core, Tokyo Medical and Dental University, Tokyo, Japan

3 Department of Joint Surgery and Sports medicine, Tokyo Medical and Dental University, Tokyo, Japan.

\section{References}

1. Dominici, M., Le Blanc, K., Mueller, I., et al. (2006). Minimal criteria for defining multipotent mesenchymal stromal cells. The International Society for Cellular Therapy position statement. Cytotherapy. 8(4), 315-317.

2. Morito, T., Muneta, T., Hara, K., et al. (2008). Synovial fluid-derived mesenchymal stem cells increase after intra-articular ligament injury in humans. Rheumatology. 47(8), 1137-1143.

3. Matsukura, Y., Muneta, T., Tsuji, K., Koga, H., \& Sekiya, I. (2014). Mesenchymal stem cells in synovial fluid increase after meniscus injury. Clinical Orthopaedics and Related Research. 472(5), 1357-1364.

4. Sekiya, I., Ojima, M., Suzuki, S., et al. (2012). Human mesenchymal stem cells in synovial fluid increase in the knee with degenerated cartilage and osteoarthritis. Journal of Orthopaedic Research. 30(6), 943-949.

5. Koga, H., Shimaya, M., Muneta, T., et al. (2008). Local adherent technique for transplanting mesenchymal stem cells as a potential treatment of cartilage defect. Arthritis Research and Therapy. 10(4), 1-10.

6. Horie, M., Sekiya, I., Muneta, T., et al. (2009). Intra-articular injected synovial stem cells differentiate into meniscal cells directly and promote meniscal regeneration without mobilization to distant organs in rat massive meniscal defect. Stem cells (Dayton, Ohio). 27(4), 878-887.

7. Hatsushika, D., Muneta, T., Horie, M., Koga, H., Tsuji, K., \& Sekiya, I. (2013). Intraarticular injection of synovial stem cells promotes meniscal regeneration in a rabbit massive meniscal defect model. Journal of Orthopaedic Research. 31(9), 1354-1359.

8. McGonagle, D., Baboolal, T.G., \& Jones, E. (2017). Native joint-resident mesenchymal stem cells for cartilage repair in osteoarthritis. Nature Reviews Rheumatology. 13(12), 719-730.

9. Roelofs, A.J., Zupan, J., Riemen, A.H.K., et al. (2017). Joint morphogenetic cells in the adult mammalian synovium. Nature Communications. 8(1), 15040.

10. Katagiri, K., Matsukura, Y., Muneta, T., et al. (2017). Fibrous synovium releases higher numbers of mesenchymal stem cells than adipose synovium in a suspended synovium culture model. 
Arthroscopy. 33(4), 800-810.

11. Kohno, Y., Mizuno, M., Ozeki, N., et al. (2018). Comparison of mesenchymal stem cells obtained by suspended culture of synovium from patients with rheumatoid arthritis and osteoarthritis. $B M C$ Musculoskeletal Disorders. 19(1), 1-9.

12. D. Smith, M. (2011). The normal synovium. The Open Rheumatology Journal. 5(1), 100-106.

13. Morita, K., Hama, Y., Izume, T., et al. (2018). Genome-wide CRISPR screen identifies TMEM41B as a gene required for autophagosome formation. Journal of Cell Biology. 217(11), 3817-3828.

14. Krenn, V., Morawietz, L., Burmester, G.R., et al. (2006). Synovitis score: Discrimination between chronic low-grade and high-grade synovitis. Histopathology. 49(4), 358-364.

15. Kanda, Y. (2013). Investigation of the freely available easy-to-use software "EZR" for medical statistics. Bone marrow transplantation. 48(3), 452-458.

16. Wojdasiewicz, P., Poniatowski, Ł.A., \& Szukiewicz, D. (2014). The role of inflammatory and antiinflammatory cytokines in the pathogenesis of osteoarthritis. Mediators of inflammation. 2014, 561459 .

17. Mathiessen, A., \& Conaghan, P.G. (2017). Synovitis in osteoarthritis: Current understanding with therapeutic implications. Arthritis Research and Therapy. 19(1), 1-9.

18. Yu, Y., Wu, R.X., Gao, L.N., Xia, Y., Tang, H.N., \& Chen, F.M. (2016). Stromal cell-derived factor-1directed bone marrow mesenchymal stem cell migration in response to inflammatory and/or hypoxic stimuli. Cell Adhesion and Migration. 10(4), 342-359.

19. Fiedler, J., Brill, C., Blum, W.F., \& Brenner, R.E. (2006). IGF-I and IGF-II stimulate directed cell migration of bone-marrow-derived human mesenchymal progenitor cells. Biochemical and Biophysical Research Communications. 345(3), 1177-1183.

20. Luo, Z., Jiang, L., Xu, Y., et al. (2015). Mechano growth factor (MGF) and transforming growth factor (TGF)- $\beta 3$ functionalized silk scaffolds enhance articular hyaline cartilage regeneration in rabbit model. Biomaterials. 52(1), 463-475.

21. Fong, D., Duceppe, N., \& Hoemann, C.D. (2017). Mesenchymal stem cell detachment with trace trypsin is superior to EDTA for in vitro chemotaxis and adhesion assays. Biochemical and Biophysical Research Communications. 484(3), 656-661.

22. Liu, S., Liu, Y., Jiang, L., et al. (2019). Recombinant human BMP-2 accelerates the migration of bone marrow mesenchymal stem cells: Via the CDC42/PAK1/LIMK1 pathway in vitro and in vivo. Biomaterials Science. 7(1), 362-372.

23. Baek, S.J., Kang, S.K., \& Ra, J.C. (2011). In vitro migration capacity of human adipose tissue-derived mesenchymal stem cells reflects their expression of receptors for chemokines and growth factors. Experimental and Molecular Medicine. 43(10), 596-603.

24. Bartok, B., Hammaker, D., \& Firestein, G.S. (2014). Phosphoinositide 3-Kinase $\delta$ regulates migration and invasion of synoviocytes in rheumatoid arthritis. The Journal of Immunology. 192(5), 20632070. 
25. Gaggioli, C., Hooper, S., Hidalgo-Carcedo, C., et al. (2007). Fibroblast-led collective invasion of carcinoma cells with differing roles for RhoGTPases in leading and following cells. Nature Cell Biology. 9(12), 1392-1400.

26. Sabeh, F., Shimizu-Hirota, R., \& Weiss, S.J. (2009). Protease-dependent versus-independent cancer cell invasion programs: Three-dimensional amoeboid movement revisited. Journal of Cell Biology. 185(1), 11-19.

27. Galgoczy, R., Pastor, I., Colom, A., Giménez, A., Mas, F., \& Alcaraz, J. (2014). A spectrophotometerbased diffusivity assay reveals that diffusion hindrance of small molecules in extracellular matrix gels used in 3D cultures is dominated by viscous effects. Colloids and Surfaces B: Biointerfaces. $120,200-207$.

28. Chen, H.-C. (2005). Boyden chamber assay. Methods in molecular biology. 294, 15-22.

29. Wallis, W.J., Simkin, P.A., Nelp, W.B., \& Foster, D.M. (1985). Intraarticular volume and clearance in human synovial effusions. Arthritis \& Rheumatism. 28(4), 441-449.

30. Owen, S., Francis, H., \& Roberts, M. (1994). Disappearance kinetics of solutes from synovial fluid after intra- articular injection. British Journal of Clinical Pharmacology. 38(4), 349-355.

31. Oefner, C., D'Arcy, A., Winkler, F.K., Eggimann, B., \& Hosang, M. (1992). Crystal structure of human platelet-derived growth factor BB. EMBO Journal. 11(11), 3921-3926.

32. Wang, C., Liu, Y., \& He, D. (2019). Diverse effects of platelet-derived growth factor-BB on cell signaling pathways. Cytokine. 113(August 2018), 13-20.

33. Demoulin, J.B., \& Essaghir, A. (2014). PDGF receptor signaling networks in normal and cancer cells. Cytokine and Growth Factor Reviews. 25(3), 273-283.

34. Sabeh, F., Ota, I., Holmbeck, K., et al. (2004). Tumor cell traffic through the extracellular matrix is controlled by the membrane-anchored collagenase MT1-MMP. Journal of Cell Biology. 167(4), 769781.

35. Mizuno, M., Katano, H., Mabuchi, Y., et al. (2018). Specific markers and properties of synovial mesenchymal stem cells in the surface, stromal, and perivascular regions. Stem Cell Research and Therapy. 9(1), 1-11.

36. Wang, S., Mo, M., Wang, J., et al. (2018). Platelet-derived growth factor receptor beta identifies mesenchymal stem cells with enhanced engraftment to tissue injury and pro-angiogenic property. Cellular and Molecular Life Sciences. 75(3), 547-561.

37. Morikawa, S., Mabuchi, Y., Kubota, Y., et al. (2009). Prospective identification, isolation, and systemic transplantation of multipotent mesenchymal stem cells in murine bone marrow. Journal of Experimental Medicine. 206(11), 2483-2496.

38. Xu, B., Luo, Y., Liu, Y., Li, B.-Y., \& Wang, Y. (2015). Platelet-derived growth factor-BB enhances MSCmediated cardioprotection via suppression of miR-320 expression. American Journal of PhysiologyHeart and Circulatory Physiology. 308(9), H980-H989.

39. Baboolal, T.G., Khalil-Khan, A., Theodorides, A.A., Wall, O., Jones, E., \& McGonagle, D. (2018). A novel arthroscopic technique for intraoperative mobilization of synovial mesenchymal stem cells. The 
Figures

A Synovium Synovial cells

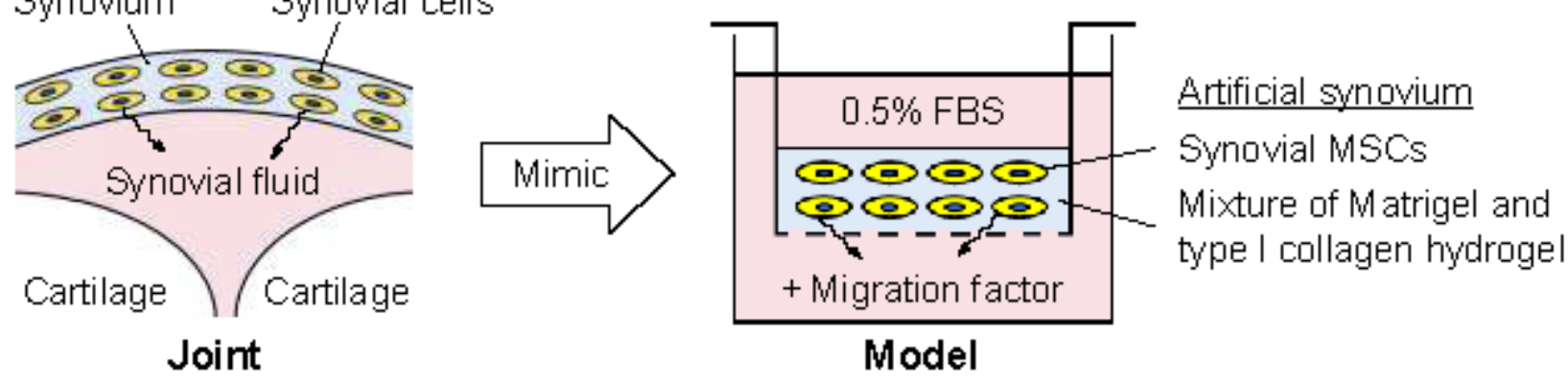

B

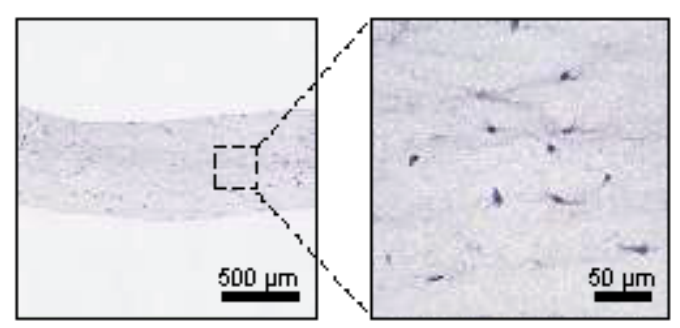

D
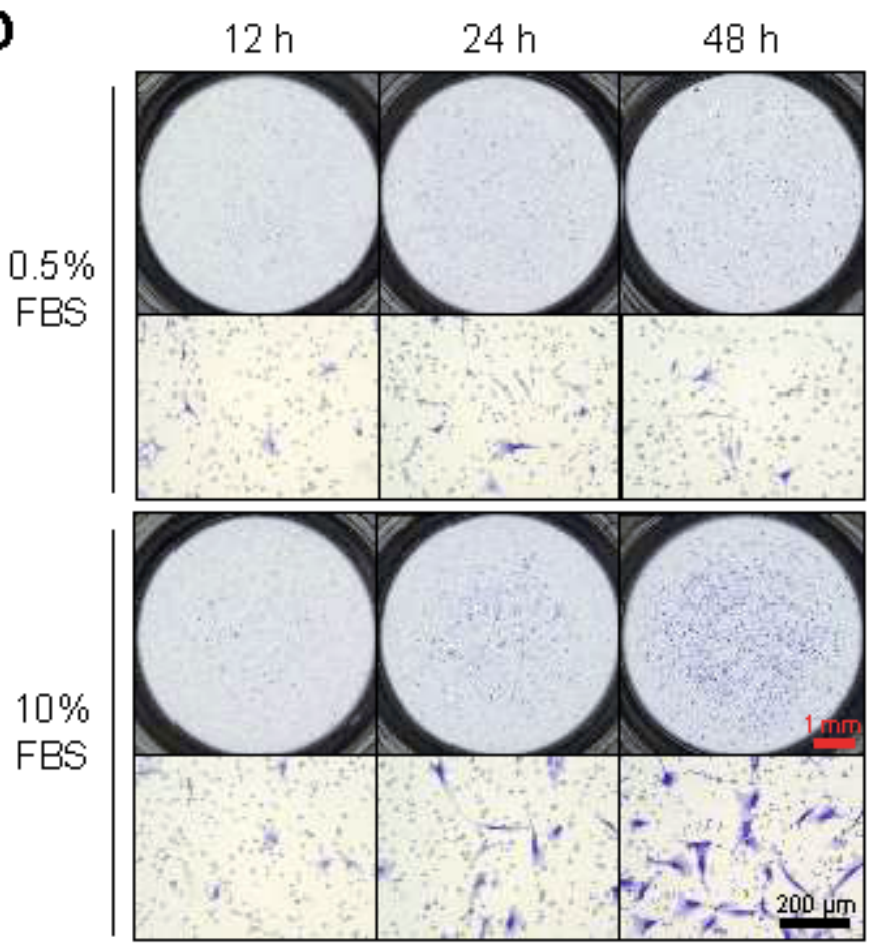

E

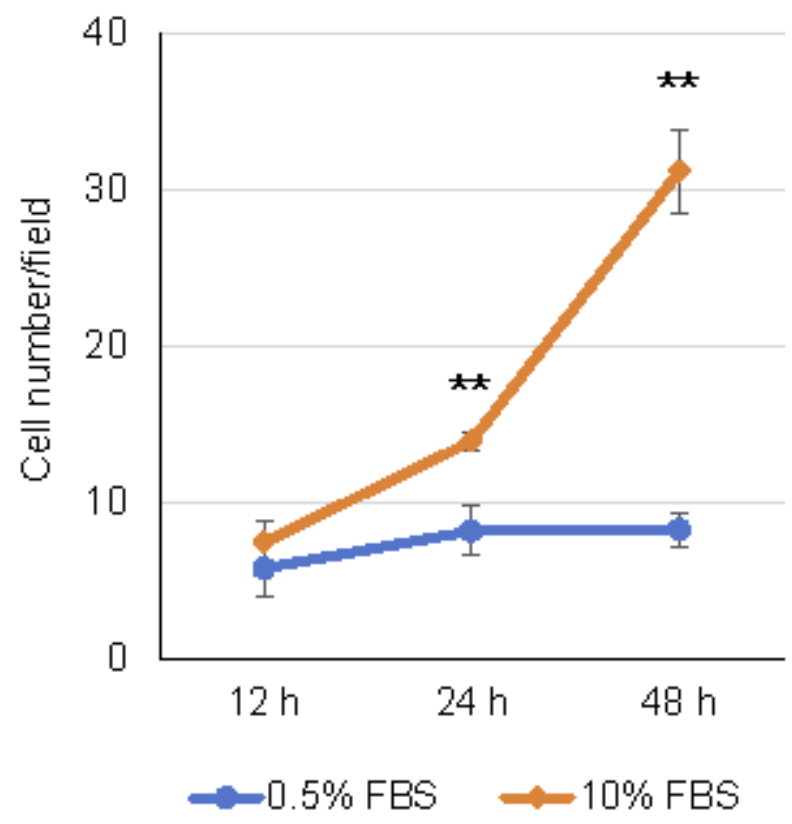

Figure 1 
A novel in vitro synovial mesenchymal stem cell (MSC) migration model. (A) Scheme of the joint and its model. The artificial synovium consisted of synovial MSCs embedded in a mixture of Matrigel and type 1 collagen hydrogel and placed on a culture insert. The insert was then placed in a medium containing migration factor. This model mimics the migration of synovial MSCs from the synovium into synovial fluid in the joints. (B) Histological section of an artificial synovium stained with hematoxylin and eosin (HE). (C) Scheme of the migration assay using $10 \%$ FBS as a migration factor. The upper chamber was filled with $0.5 \%$ FBS and the lower chamber was filled with either $0.5 \%$ as a negative control or $10 \% \mathrm{FBS}$ as a positive control. The migrated cells on the lower side of the insert were counted after 12,24 , and 48 h. (D) Migrated cells stained with crystal violet. (E) The number of migrated cells per field. The average and SD are shown $(n=3) .{ }^{* *} p<0.01$ by Student's t-test between two unpaired groups.

A

$24 \mathrm{~h}$

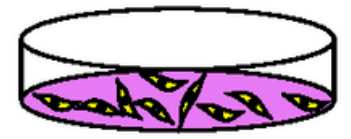

$48 \mathrm{~h}$

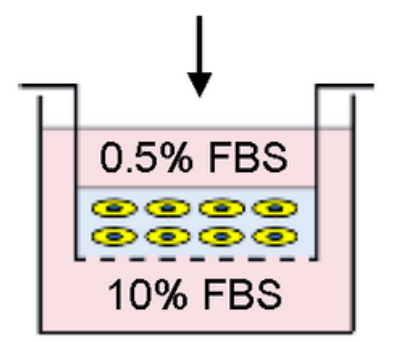

$0.5 \%$ FBS
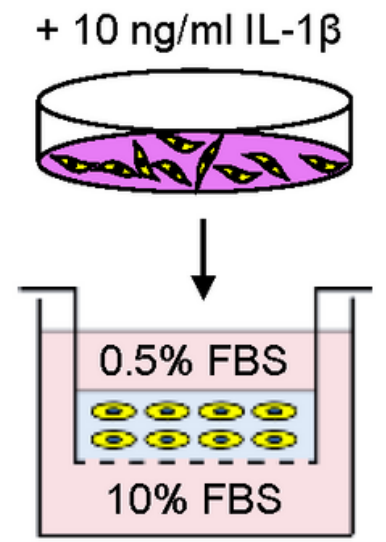

$0.5 \%$ FBS

$+10 \mathrm{ng} / \mathrm{ml}$ TNF- $\alpha$
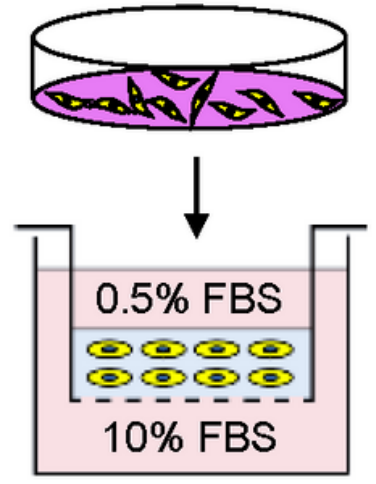

B

Control

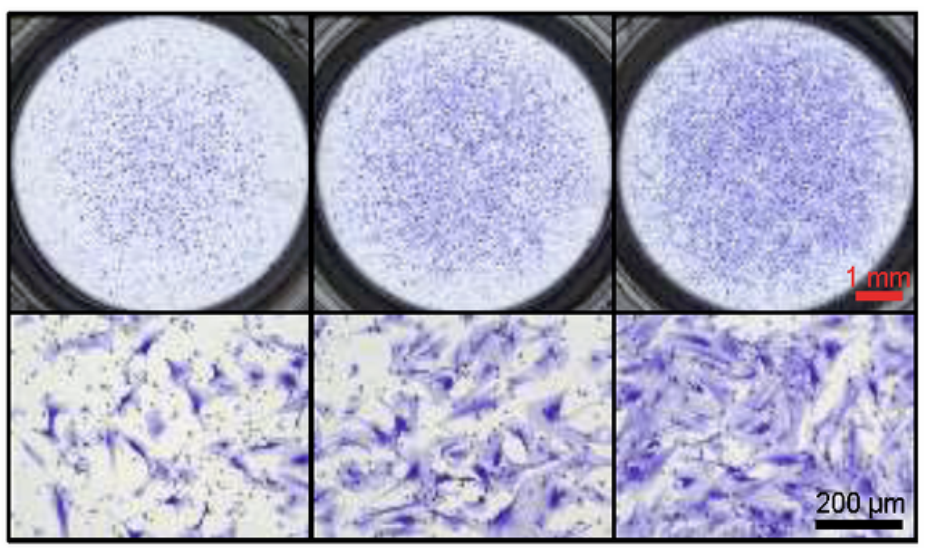

IL-1 $\beta$

TNF- $a$

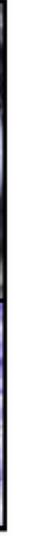

C

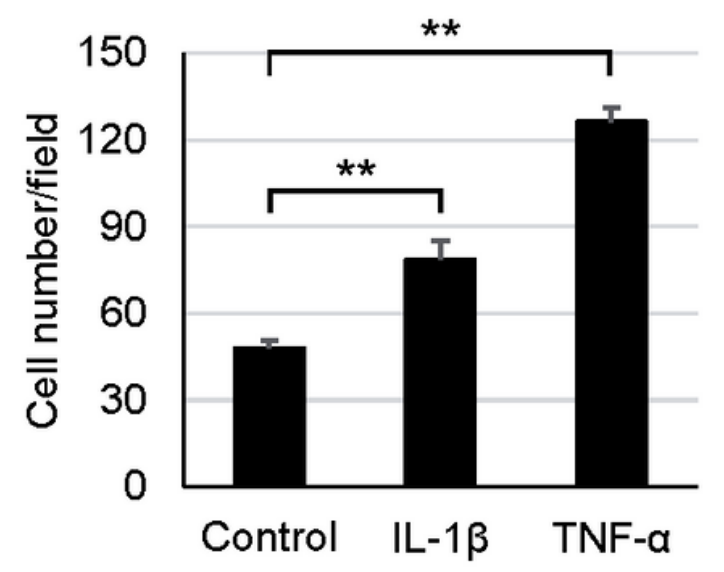

Figure 2

The effect of pretreatment with inflammatory cytokines on the migration of synovial MSCs. (A) Scheme of the experiment. Human synovial MSCs were pretreated with IL-1 $\beta$ or TNF- $\alpha$ for $24 h$, and then subjected to the migration assay for $48 \mathrm{~h}$. (B) Migrated cells stained with crystal violet. (C) The number of migrated 
cells per field $(n=3) .{ }^{\star \star} p<0.01$ by one-way analysis of variance followed by Dunnett's multiple comparisons test.

A

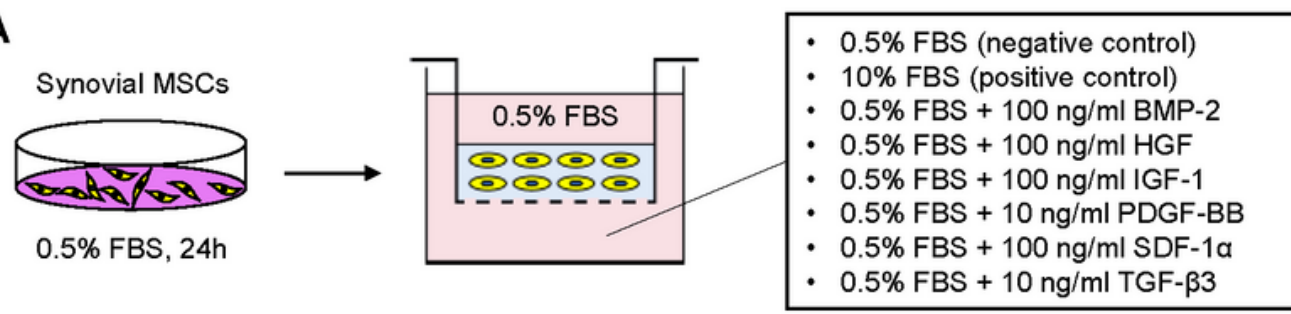

B
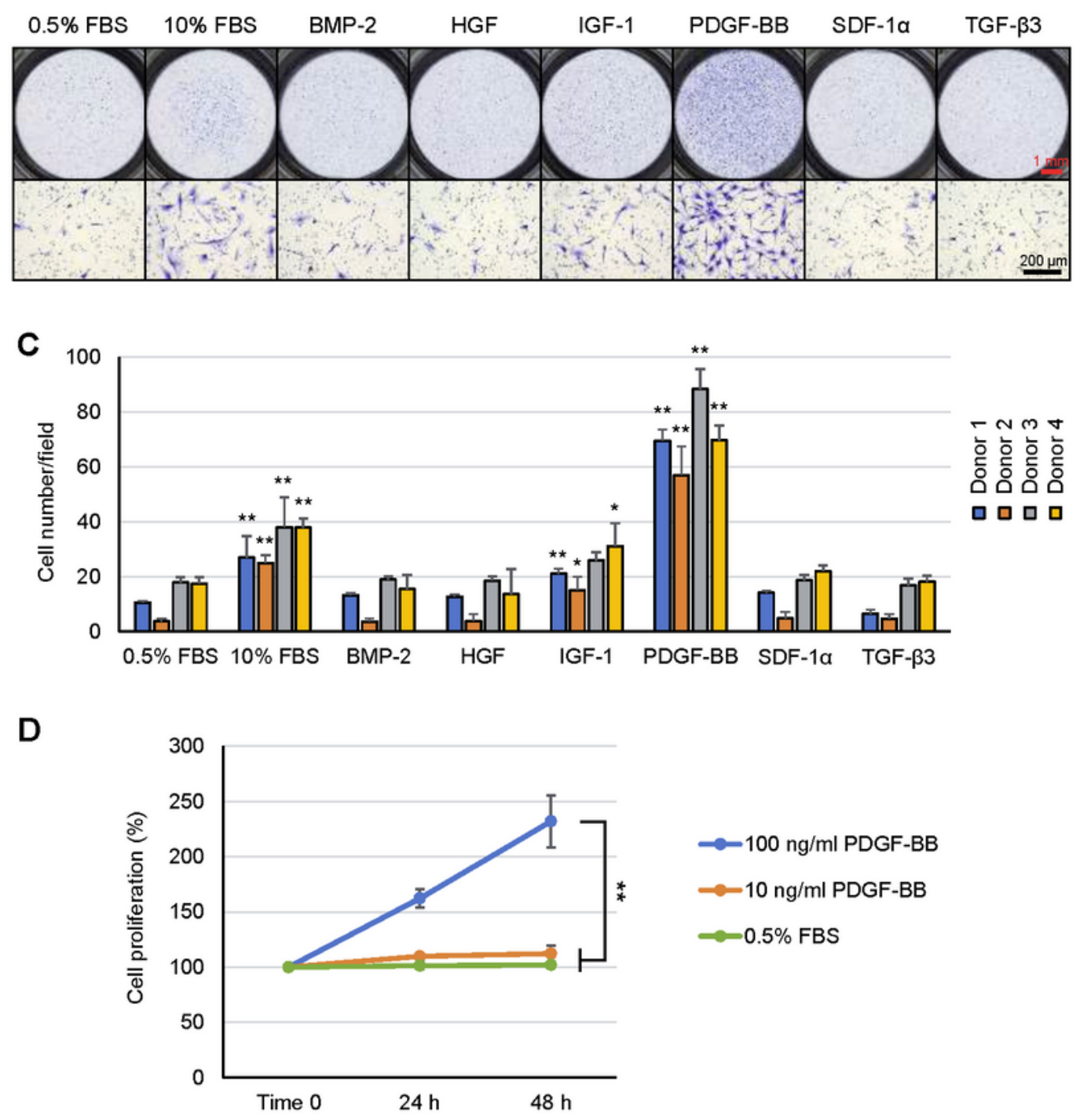

\section{Figure 3}

Effects of various cytokines on synovial MSC mobilization. (A) Scheme of the experiment. Synovial MSCs were cultured with $0.5 \%$ FBS for $24 \mathrm{~h}$ and embedded in a hydrogel. Various cytokines were added to the lower chamber and the cells were cultured for 48 h. (B) Migrated cells stained with crystal violet. (C) 
The numbers of migrated cells per field. The results from four donors are shown separately $(n=3)$. * $p<$ $0.05 ;{ }^{*} \mathrm{p}<0.01$ versus $0.5 \%$ FBS by one-way analysis of variance followed by Dunnett's multiple comparisons test. (D) PDGF-BB effects on proliferation of human synovial MSCs $(n=4)$. The cell number at time 0 was set at $100 \% .{ }^{* *} p<0.01$ by one-way analysis of variance, followed by Tukey's multiple comparisons test.

A

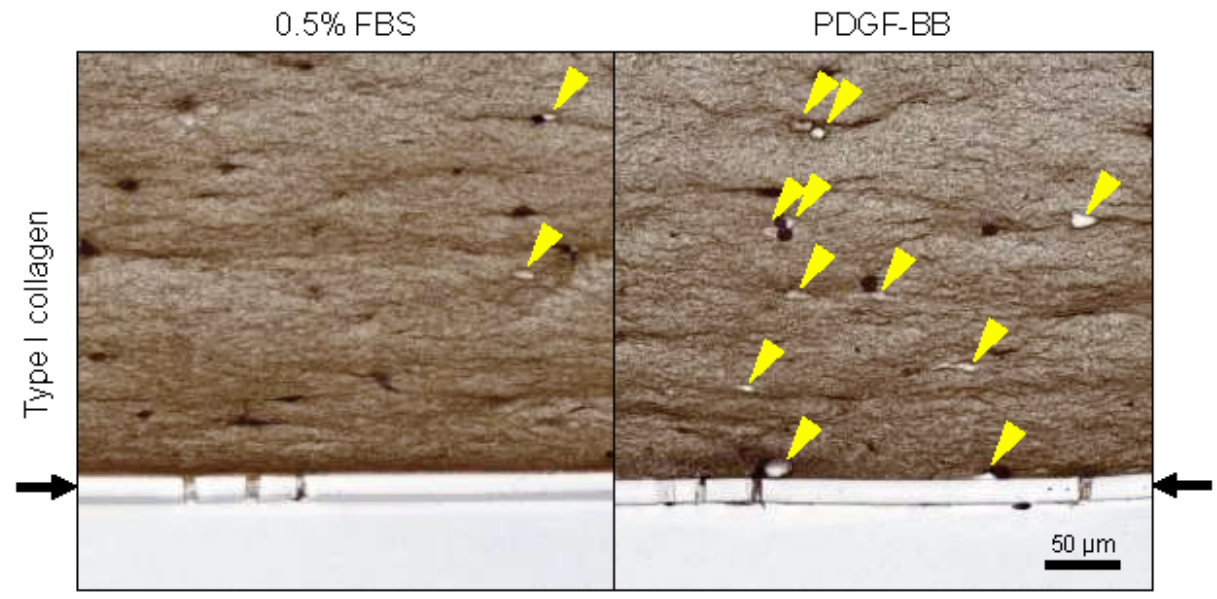

B

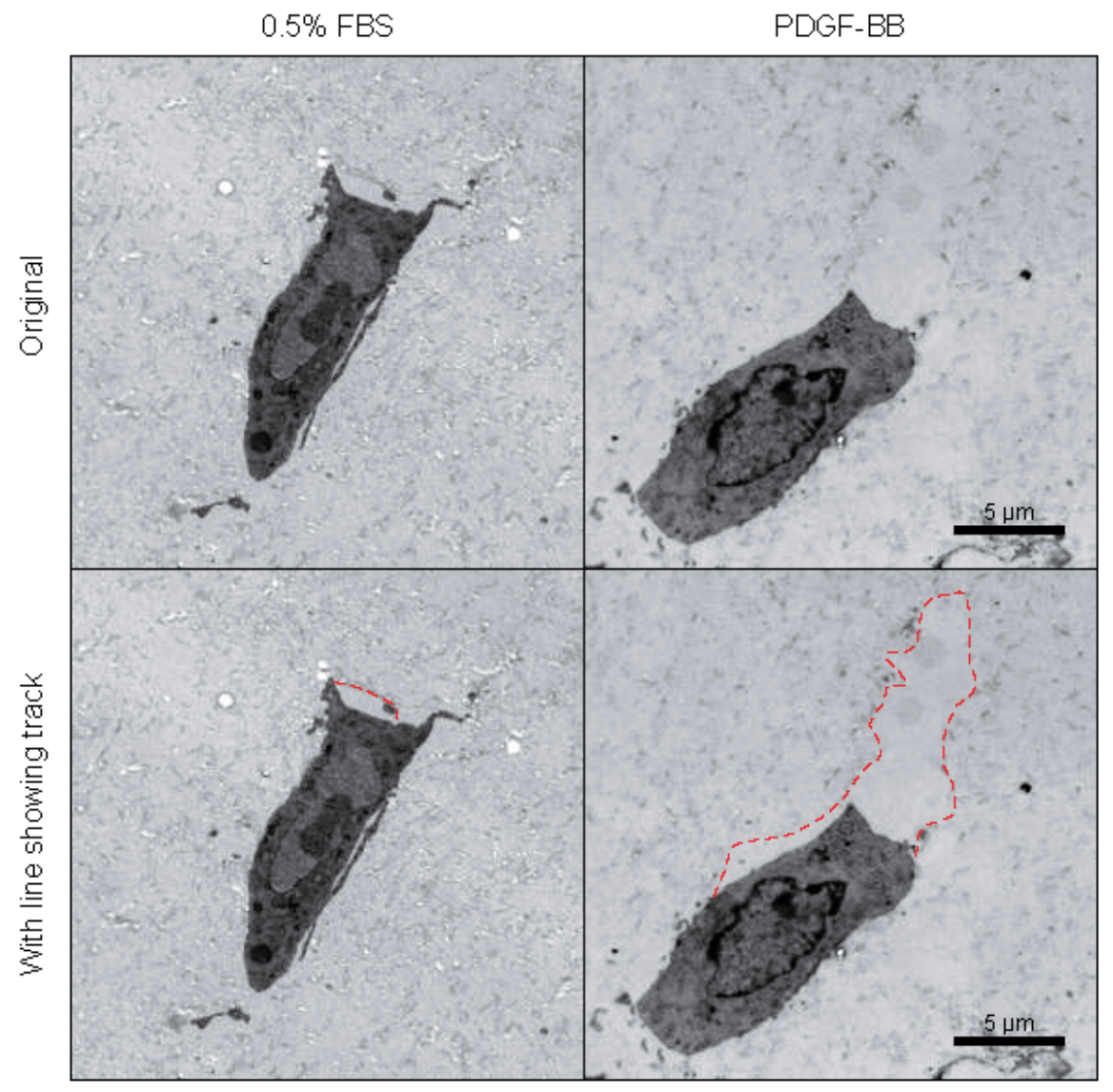

Figure 4 
Tracks left in the matrix following the mobilization of human synovial MSCs. (A) Representative images of the hydrogels immunostained for type I collagen. Yellow arrowheads indicate the tracks in the matrix. Black arrow shows a transwell with pores. (B) Representative TEM images of human synovial MSCs embedded in the hydrogel. Dotted lines indicate the borders of the tracks adjacent to the cells.

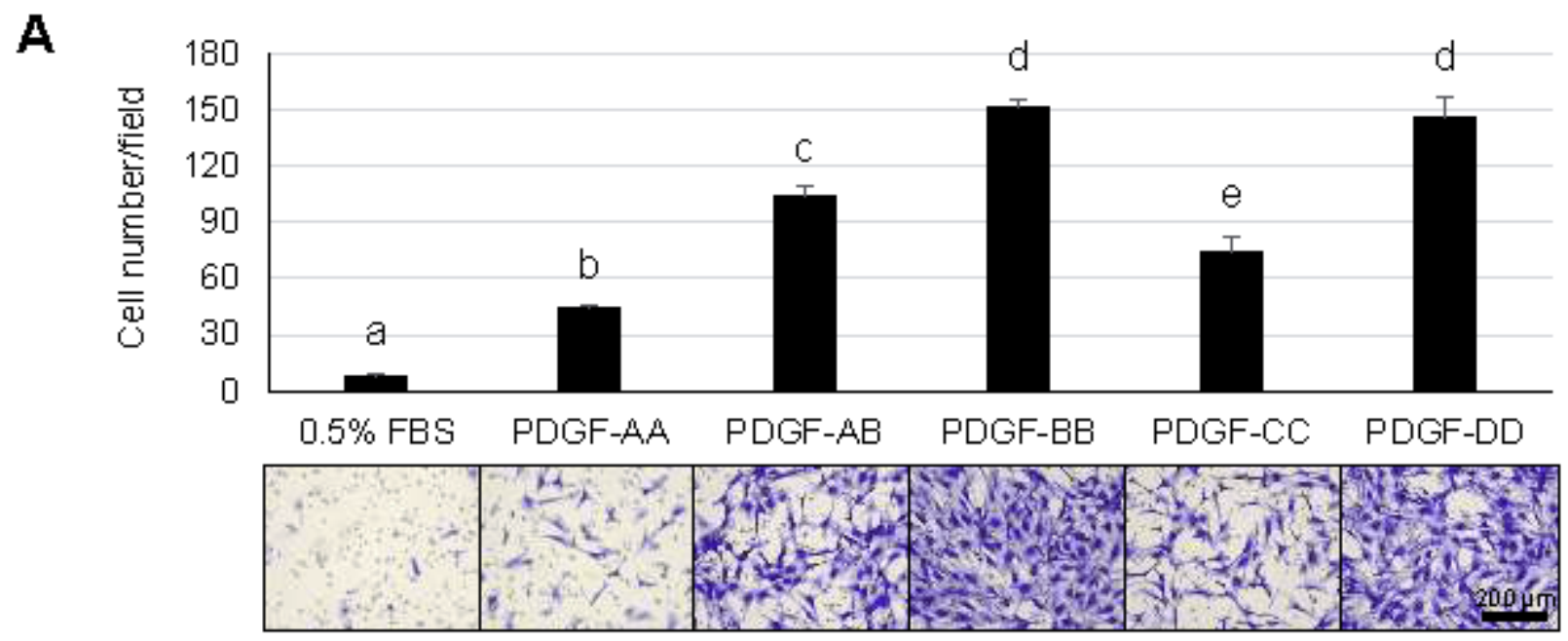

B
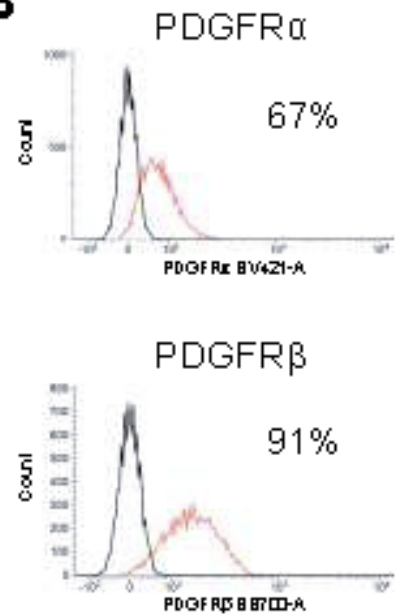

C $100, \quad b$

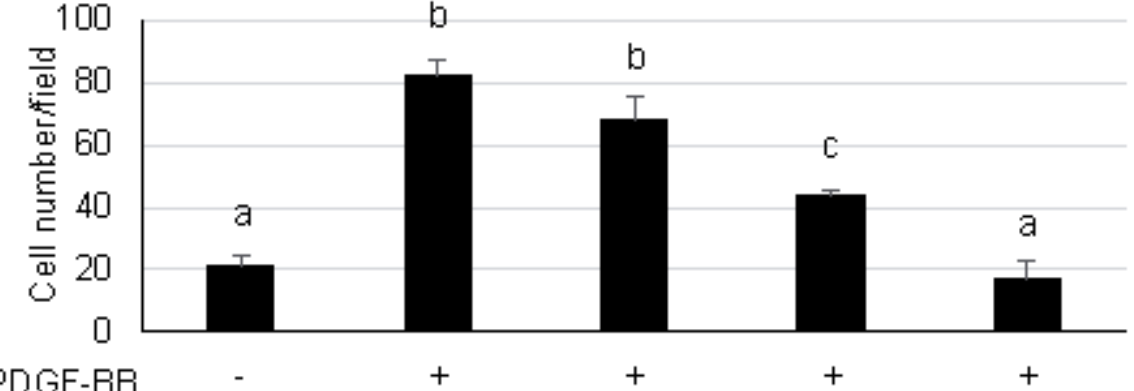

PDGF-BB Crenolanib
$0 \mu \mathrm{M}$

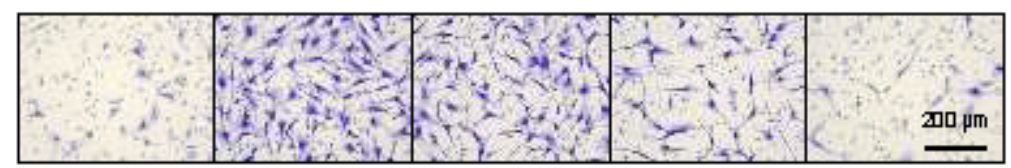

\section{Figure 5}

The effect of PDGF signaling on mobilization of human synovial MSCs. (A) Comparison of the effectiveness of PDGF isoforms for mobilizing synovial MSCs. The number of migrated cells per field $(n=3)$ and representative images of migrated cells stained with crystal violet are shown. All groups that do not share common letters are significantly different $(p<0.05)$ by one-way analysis of variance followed by Tukey's multiple comparisons test. (B) Histograms of PDGFRa and $\beta$ expression in human synovial MSCs. Black line indicates the isotype control. (C) The effect of crenolanib, a PDGFR inhibitor, on PDGF-BB-induced migration of synovial MSCs. The number of migrated cells per field $(n=3)$ and representative images of migrated cells stained with crystal violet are shown. 

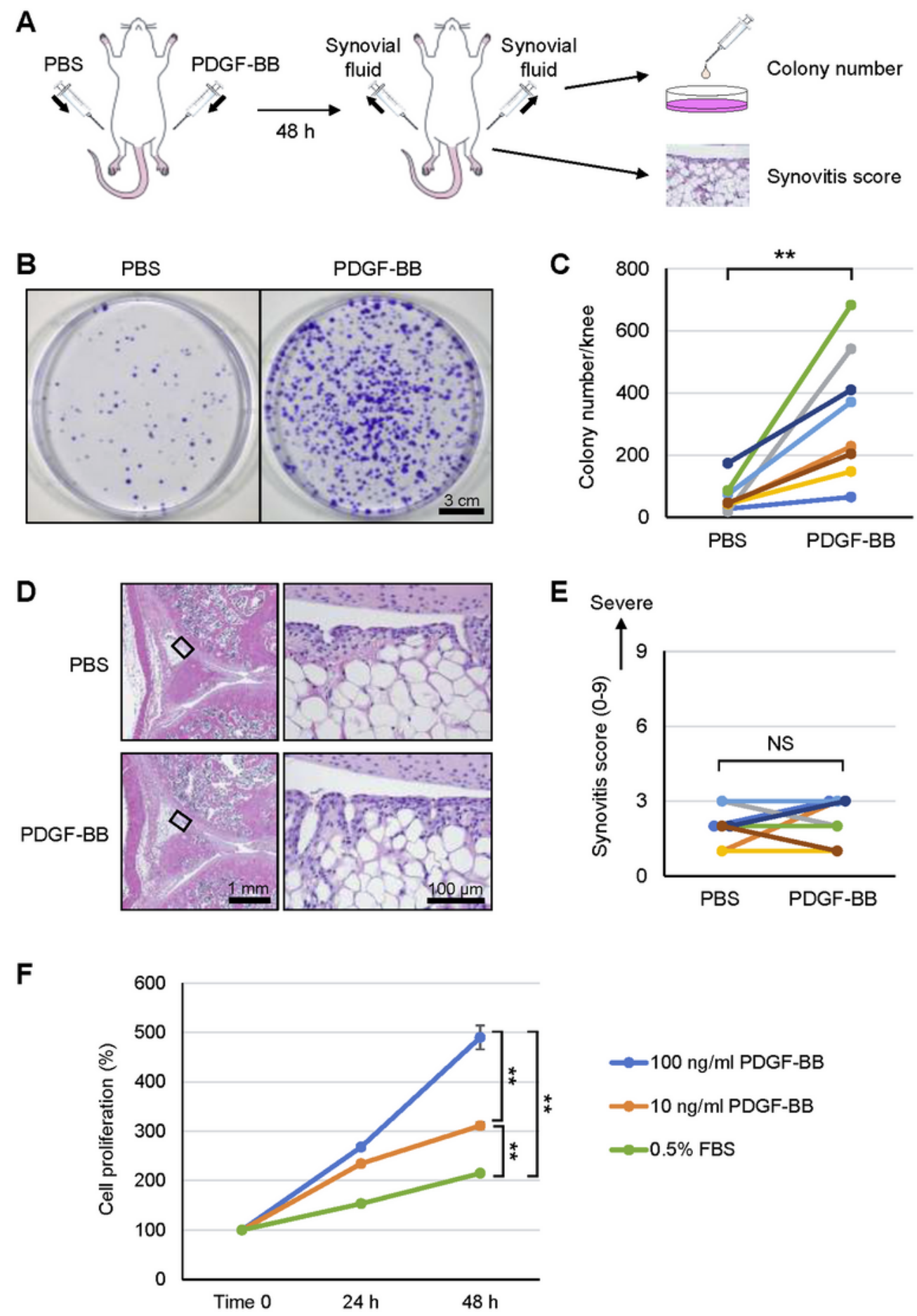

\section{Figure 6}

The effects of intra-articular injection of PDGF-BB on numbers of colony-forming cells in synovial fluid and on the development of synovitis in rat knees. (A) Scheme of the experiment. PDGF-BB or PBS was injected into a rat knee. Synovial fluid was aspirated $48 \mathrm{~h}$ later, plated on a dish, and cultured for seven days. At the same time, the knee was histologically evaluated. (B) Colony formation seven days after synovial fluid was plated and cultured. Cell colonies were stained with crystal violet. (C) Colony number 
per knee. ${ }^{* \star} p<0.01$ by Wilcoxon signed rank test $(n=8)$. (D) Representative histological images of synovium stained with hematoxylin and eosin (HE). (E) Synovitis scores. The scores for the PBS-treated $(n=8)$ and PDGF-BB-treated knees $(n=8)$ were not significantly different $(p=0.572$ by Wilcoxon signed rank test). (F) PDGF-BB effects on the proliferation of rat synovial MSCs $(n=3)$. The cell number at time 0 was set at $100 \%$. ${ }^{* *} p<0.01$ by one-way analysis of variance, followed by Tukey's multiple comparisons test.
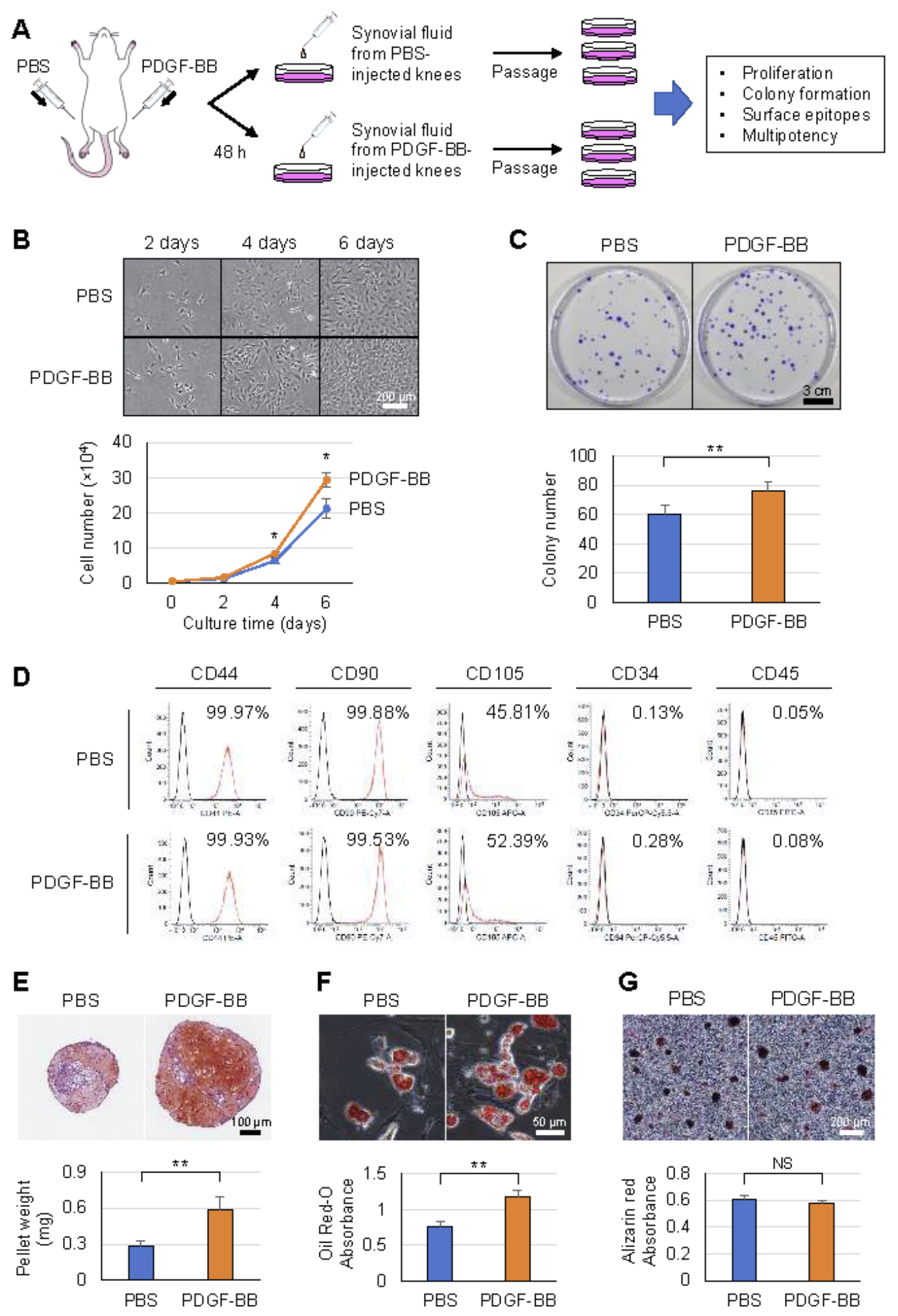

Figure 7 
Properties of colony-forming cells in rat synovial fluid after PDGF-BB injection. (A) Scheme of the experiment. PDGF-BB or PBS was injected into a rat knee. Synovial fluid was aspirated $48 \mathrm{~h}$ later, cultured for seven days, and passaged. The cells at passage 1 were used for the experiment. (B) Cell morphology and the number of cells at days 2,4 , and $6(n=3)$. (C) Colonies stained with crystal violet and colony number after 14 days of culture $(n=6)$. (D) Surface epitopes. Black line shows the isotype control. $(E)$ Cartilage differentiation. Histological sections stained with Safranin $\mathrm{O}$ and cartilage pellet weight are shown ( $n=6)$. (F) Adipogenic differentiation. Lipids stained with Oil Red $O$ and the absorbance of extracted dye at $510 \mathrm{~nm}$ are shown $(n=6)$. (G) Calcification. Calcified cells stained with alizarin red and the absorbance of the extracted dye at $560 \mathrm{~nm}$ are shown $(n=6) .{ }^{*} p<0.05 ;{ }^{* *} p<0.01$ by Student's t-test between two unpaired groups.

\section{Supplementary Files}

This is a list of supplementary files associated with this preprint. Click to download.

- EndoPDGFBBSCRRGraphicalabstract210308.pptx 